\section{THE TREATMENT OF MASTITIS.}

By CHARLES J. WRIGHT, M.R.C.S.,

Surgeon to the Hospital for Women and Children at Leeds ; Lecturer on Midwifery at the Yorkshire College.

Mx object is to direct attention to the beneficial effects of pressure in the treatment of milk-engorgement and ordinary inflammatory diseases of the breast.

In cases of painful lactation and puerperal mastitis, where the breast is swollen and indurated-whether suppuration threaten or not-we have been accustomed to direct that the mammary gland should be raised and supported by a suspensory bandage or handkerchiof. Strapping with ordinary adhesive-or sometimes lead or belladonna-plaster has been practised both before and after suppuration, to the great comfort of the patient; but I doubt whether we have hitherto realised the benefit derived from a firm and equable pressure by a carefully-adjusted bandage placed over the opposite shoulder and round the chest, so as not only to support, but to uniformly compress, the mammary gland, or that we have sufficiently profited by the results of this practice systematically carried out. The comfort to the patient is immense ; and, whether suppuration take place or not, the treatment may be continued up to the moment that the pus is evacuated, and from that time until the part is well.

Dr. G. Ranney, of Michigan, U.S., in a paper read before the Section of Obstetric Medicine at the Brighton meeting of the British Medical Association, drew attention to the good results of the pressure treatment; and I bring it before this Society, as the method I advocate does not receive much, if any, notice in the English or American text-books.

The following cases will illustrate the points to which I wish to direct attention.

CASE I. - Mrs. - - aged 43, was delivered of her eighth child, after a natural labour, on Octuber 3rd. She made a good recovery, and I paid my last visit on October 18th. She had suckled all her children but two, one of which was stillborn. With her fourth child the milk failed her ; this time there was from the first a good supply.

October $27 \mathrm{th}$, the twenty-fourth day after delivery, I found the right breast hard, hot, and tender. A belladonna lotion was applicd, the gland was slung up after being emptied with the breast glass, and the child cut off from it, and allowed to take from the other just sufficient to prevent it getting too full.

On October 31st, finding it difficult to support the breast with comfort, I proceeded as follows:-Having laid on a piece of lint noistened with belladonna lotion, and padded the breast with wadding, I took a calico roller, four inches wide and six yards long, and wrapped it firmly and evenly round the chest and over the opposite shoulder, alternately fixing the folds with safety pins as I proceeded, thus getting an uniform pressure over the whole of the affected mammary gland. The comfort was very marked and immediate, and it was no less interesting than remarkable to notice that deep finger pressure on any one spot gave acute pain, but immense relief was experienced on uniformly applying firm pressure with the bandage. The right arm was kent as much as possible in a sling, but not ban. daged to the side. This process was repeated daily for the next five days, the nipple being drawn slightly by an exhausting glass on each occasion.

On the sixth day of the application, finding fluctuation, I made an opening near the areola, under the carbolic spray, and let out about one ounce of pus. A drainage-tube was inserted, covered by a dressing of warm moistened sublimated wood-wool wadding, and a flannel bandage applied as before. This dressing was changed under spray on the second, fourth, seventh, and eleventh days after the opening was made, the part each time being firmly bandaged. No more pus exuded, and on the fourth dressing the abscess was completely healed. A piece of Gamgee tissue, powdered with iodoform, was plaeed over the nipple, and the pressure treatment continued. As the other broast contained much milk, and the patient was anxious to nurse, the child was allowed to use it. This caused a little difficulty in applying the bandage, as it had to be fixed with safety pins, chiefly round one side, so as to avoid constricting the actively secreting gland.

For two days I tried a broad elastic bandage, and, although it was a. great comfort to the inflamed organ, it pressed too much on the active one, and had to be discontinued. As some thickening and hardness remained a month after the pus was evacuated, some firm strapping was applied in addition to the bandage. A continuation of this treatment cleared up the case. Some milk exuded from the nipple of the affected breast at each dressing, and it still (March,
1887) oozes at intervals, but it has not been deemed safe to resume the nursing with it.

CASE II.-An unmarried girl, aged 17 , came to my out-patient room at the hospital on December 14 th. Six weeks previously she was struck by a friend in play with the back of the hand over the right breast, which on admission was large, hard, and tender, foeling boggy, as if about to suppurate, on the outer side and near the nipple. She was taken in and put to bed, and a long, soft double napkin bound round both breasts, and firmly fixed with safety-pins. Two days afterwards the broad flannel roller was applied, and changed every few days. The temperature, which was $102.6^{\circ} \mathrm{F}$. upon admission, came down to normal on the third day of the treatment. At first I hoped that we should avoid suppuration; but the temperature again rose, and I had eventually to make an opening, nearly four weeks after admiosion, and evacuated a large quantity of pus. This case is now well, after somewhat prolonged drainage, combined with bandaging or strapping throughout.

It was, however, worthy of note that in this case the pressure was such a comfort to the patient that it rather masked the condition when suppuration had actually taken place. It is, therefore, essential to be more especially on the watch for fluctuation where pain is practically in abeyance.

I have found this method of great use in other cases of painful breasts-1, in which a lady tried to nurse her child, but failed to have milk enough ; 2 , where milk was present in the breasts, but the mother was unwilling to persevere with lactation ; 3 , in a case of persistent mammary pain after abortion at two months; 4 , in a patient who had reasons for not nursing a first child, though the milk was plentiful and the breasts very full and tender. In these cases the napkin fastened with pins was sufficient, and the tighter it was drawn the greater was the comfort to the patient. In the latter case, plasters also were used; but in future I shall endeavour to dispense with them in cases of simple suppression of lactation. It seems as if the pressure upon the acini and lactiferous ducts prevents, or at all events limits, secretion and accumulation in the gland, and encourages the absorption of inflammatory products, limiting considerably the area of suppuration when this takes place, and favouring the healing process after evacuation. The relief experienced in all $\mathrm{my}$ cases was most marked.

I have also tried the pressure treatment in other painful conditions of the puerperium ; for example, in a case of severe perimetritic pain occurring within a week of delivery, where there was undoubtediy some peritonitis, pressure carefully applied over a poultice with a pad of wadding over the most tender ovarian region gave decided relief.

It is now, I hope, unnecessary to dwell upon the advantages of opening mammary abscess antiseptically, the great saving in time, trouble, suffering, and cleanliness to both patient and nurse admitting, I think, of no question; a small Siegle's steam-spray or a hand-spray is sufficient if the ordinary apparatus is not available; and Sir Joseph Lister has described a plan by which antiseptic precautions may be maintained without even using any spray.

Further experience will define the cases to which the pressure treatment is inapplicable; but at least in the ca $\theta ; I$ have noted it is pleasant to contemplate the difference between pressure with comfort and Listerism, with rapid recovery, on the one hand, and the troublesome discomfort of slings and prolonged poulticing, with discharge for weeks or months, and the sinuses and re-formed abscesses healing with ugly scars, the result of the older treatment.

\section{ON THE TREATMENT OF CONICAL CORNEA BY THE ACTUAL CAUTERY.}

BY W. J. CANT, M.R.C.S.ENঞ., L.R.C.P., Lincoln.

I wish to bring before your notice what seems to me to be a most surcessful operation for conical cornea, which was first suggested and performed by the late Dr. Edwyn Andrew, of Shrewsbury, who reported a case where the operation improved the vision from is of the normal to $\frac{3}{7}$. When one sees a case of conical cornea, a sense of helplessness is always felt, as the transparent cornea is thinned and bulged, distant and near vision bad, from the irregular astigma tism produced, the patient also being in delicate health. Glasses, tonics, and local applications are almost useless, and relief can only be obtained by operation, which, in the cases I shall mention, is done by making a minute opening through the centre of the cone with a heated needle cautery. The operations now in most favour are performed by removing a piece of the cornea from the centre of the cone by the knife or trephine, which, besides being rather difficult to do, 